\title{
Implementasi Akad Ijarah-Asset To Be Leased pada Transaksi Sukuk Ritel di Bank Syariah Mandiri cabang Jombang
}

\author{
Imam Azizuddin \\ Universitas Islam Negeri Maulana Malik Ibrahim Malang \\ Email: imamazizuddin@uin-malang.ac.id
}

Abstract : Retail sharia bond/sukuk (sharia obligation) becomes investors' most favorable retail. It is reflected by the high demand of obligation in every implementation of emission accomplished. This research aims to know the implementation of ijara - asset to be leased agreement on the retail sharia bond transaction, and the constraint faced by banks in its implementation. This research uses a descriptive qualitative approach which elaborates the result of observation on the implementation of ijara - asset to be leased agreement on the retail sharia bond transaction. It is then explicated in form of narration and implementation scheme. The instruments are primary data which are collected directly from the informants and secondary data in form of literatures, product brochures, and previous researches. The result shows that the agreement used by bank in the implementation of Ijarah - Asset to be Leased agreement on the retail sharia bond transaction contains trading agreement (al-bay') of the underlying asset. The use of wakalah agreement is required when the right to issue sukuk as a representative in the sukuk rental process to the underwriter. On the other hand, a kafalah agreement is required when the right to issue emissions provides guarantees to sukuk management agencies issued. The constraints faced by the bank in the implementation are the fact that the society is still lack of information about sukuk and the customers of retail sharia bond still has incomplete administration data.

Keywords $\quad$ : Ijara, Ijara-Asset To Be Leased; Retail Sharia Bond;

Abstrak : Munculnya sukuk ritel (obligasi syariah) merupakan yang paling banyak diminati oleh investor, yang tercermin dari tingginya permintaan atas obligasi dalam setiap pelaksaan emisi yang dilakukan. Tujuan dari penelitian ini adalah untuk mengetahui implementasi akad ijarah - asset to be leased pada transaksi sukuk ritel, serta kendala-kendala bank dalam mengimplementasi sukuk ritel. Penelitian ini menggunakan pendekatan kualitatif deskriptif yang memaparkan hasil observasi pelaksanaan implementasi akad ijarah - asset to be leased pada transaksi sukuk ritel yang kemudian dijelaskan dalam bentuk narasi dan skema pelaksanaannya. Dengan instrumen berupa data primer yang diperoleh langsung oleh beberapa narasumber dan data sekunder dalam bentuk pustaka, brosur produk, dan penelitian terdahulu. Dan hasilnya, secara umum bahwa akad yang diguanakan bank dalam Implementasi akad Ijarah - Asset To Be Leased Pada transaksi sukuk ritel juga terdapat akad jual beli (al-bay') atas underlying asset. Penerapan akad wakalah dibutuhkan ketika yang berhak menerbitkan sukuk sebagai wakil dalam proses sewa sukuk kepada penjamin emisi. Disisi yang lain akad kafalah dibutuhkan Ketika yang berhak menerbitkan emisi memberikan jaminan kepada Lembaga pengelola sukuk yang yang diterbitkan. Untuk kendala yang dihadapi oleh bank dalam pelaksanaannya yaitu masyarakat sekitar bank yang masih belum banyak mengetahui tentang apa itu sukuk serta masih kurangnya kelengkapan data administrasi nasabah sukuk ritel.

Kata Kunci : Ijarah; Ijarah-Asset To Be Leased; Sukuk Ritel

\section{A. Pendahuluan}

Perkembangan dunia ekonomi dewasa ini telah mengalami kemajuan yang sangat pesat, hal ini menuntut para pelakunya untuk selalu berinovasi dalam pelaksanaanya. Berbagai macam inovasi keekonomian dilakukan agar apa yang diinginkan dapat terpenuhi, tidak terkecuali dunia perbankan di Indonesia.

Sejarah mencatat perbankan syariah pertama baru lahir tahun 1991 dan beroperasi secara resmi tahun 1992. Hal ini jelas merupakan angin segar dalam sektor perbankan khusunya perbankan syariah di Indonesia. Terlebih pada saat Indonesia mengalami krisis moneter, kehadiran perbankan syariah sebagai bank yang tidak mengalami kebangkrutan mencerminkan kesuksesan perbankan syariah dalam sistem dan operasionalnya. 
Melihat peluang bisnis syariah yang semakin pesat, maka semakin gencar pula inovasi yang dilakukan, salah satu inovasi yang dilakukan adalah dengan adanya berbagai macam jenis investasi syariah, seperti investasi saham syariah, reksa dana syariah, sukuk ritel obligasi syariah), dan juga investasi dinar syariah. Sukuk bisa digunakan sebagai parameter pesatnya perkembangang dari keuangan syariah, walaupun pengistilahan sukuk itu sudah tidak menjadi hal yang baru dalam sejarah perkembangan ekonomi syariah ${ }^{1}$.

Istilah Sukuk sering disebut dengan obligasi Syariah. Dalam fatwa DNS menggunakan Istilah obligasi Syariah sejatinya lebih pada mengikuti opini pasar modal konvensional. Namun keduanya sangat berbeda antara surat berharga Syariah serta surat berharga konvensional. Pada obligasi Syariah dalam penerapan sistem pengembalian menggunakan bagi hasil, fee dan margin. Sukuk adalakalnya dijelaskan dengan nama obligasi (surat berharga) berisikan kontrak pembiayaan berprinsip Syariah ${ }^{2}$.

Masyarakat Indonesia saat ini sangat mempunyai kemauan yang besar dalam investasi berupa sukuk ritel yang mulai berkembang. Keinginan masyarakat ini bisa sangat dipengaruhi dari beberapa aspek, sehingga dalam penerbitan sukuk mengalamai kenaikan jumlah sangat pesat. Pertama, perusahaan yang menggunakan manfaat dari sukuk ini sangat banyak jumlahnya, karena bisa dibilang sukuk dipasar modal Syariah menjadi alternatif sumber pembiayaan. Kedua, pemodal (investor) sudah tidak lagi harus menggunakan dana yang besar dalam melakukan investasi, karena dengan sukuk ini sangat membantu atas kemampuan para investor dlam menanamkan investasi syariah. dan ketiga pasar modal di Indonesia yang mengalami kondisi perekembangan yang lumayan kondusif serta mempunyai prospek yang cerah.

Umumnya perbankan syariah sebagai agen antara pemerintah sebagai emiten dan masyarakat sebagai pemegang sukuk ritel menerapkan berbagai macam akad dalam transaksi sukuk, seperti surat berharga syariah mudharabah, surat berharga syariah murabahah, surat berharga syariah musyarakah, surat berharga syariah salam, surat berharga syariah istishna', dan surat berharga syariah ijarah. akan tetapi saat ini baru terdapat dua jenis sukuk yang digunakan di Indonesia yaitu obligasi syariah mudharabah dan obligasi syariah ijarah ${ }^{3}$. Sedangkan pada akad ijarah pun masih dibagi kedalam beberapa sub bab tertentu seperti ijarah - lease and back dan ijarah - asset to be leased.

Keberhasilan yang telah dicapai perbankan syariah bisa dibilang hasil dari upaya bank syariah sejak tahun 1992 dan selalu terus dikembangkan ditahun berikutnya. Bank syariah ialah bank yang dalam menjalankan kegiatan perbankan berasaskan pada hukum islam. Semua kegiatan yang dijalankan selaras dengan Al-Qur'an dan Al-Hadist, khususnya yang berhubungan dengan tata cara bermuamalah secara islam ${ }^{4}$. Alasan dilakukan Penelitian di PT. Bank Syariah Mandiri Cabang Jombang dikarenakan Bank Syariah Mandiri merupakan bank Syariah yang menjadi mitra distribusi ritel sukuk terbaik tahun 2019. Dengan begitu peneliti dapat mengetahui bagaimana implementasi ijarah yang ada di PT. Bank Syariah Mandiri Cabang Jombang bisa menjadi penopang keberhasilan dalam memperoleh penghargaan sesuai prinsip syariah $^{5}$.

${ }^{1}$ Al-Tijary Jurnal et al., "Peran Sukuk Negara Dalam Pembiayaan Infrastruktur," core.ac.uk 2, no. 2 (2017): 155-176.

${ }^{2}$ Iyah Faniyah, Kepastian Hukum Sukuk Negara Sebagai Instrumen Investasi Di Indonesia, ed. Laurensius Arliman Simbolon, pertama. (Sleman: Deepublish, 2018): 47.

${ }^{3}$ Andri Soemitra, Bank \& Lembaga Keuangan Syariah (Jakarta: Prenada Media, 2017): 85.

${ }^{4}$ Malayu S.P Hasibuan, Dasar-Dasar Perbankan (Jakarta: Bumi Aksara, 2009): 125.

${ }^{5}$ Madiri Syariah, "Sukuk Negara Retail." 
Untuk memberikan penguatan terhadap penelitian yang akan penulis lakukan, perlu kiranya membangun konsep dengan hasil penelitian - penelitan yang sudah pernah dilakukan untuk mendukung dan memperkuat penelitian ini. Penelitian tersebut merupakan hasil dari Faizul Rahman, Ardi Paminto, Maryam Nadir (2016) ${ }^{6}$ yang berjudul "Pengaruh Harga Sukuk Negara Ritel Seri 005, Tingkat Inflasi, dan BI Rate terhadap Tingkat Permintaan Sukuk Negara Ritel Seri 005”. Penelitian kuantitatif ini menggunakan populasi sukuk negara ritel seri 005 dengan sampel data dari harga pasar dan volume penjualan bulanan dari sukuk negara ritel seri 005 untuk periode Maret 2013 sampai dengan Pebruari 2016. Skripsi oleh Syfa Hanifah Intisar (2017) ${ }^{7}$ Pelaksanaan Akad Ijarah Asset To Be Leased Surat Berharga Syariah Negara Ritel (Seri SR-008), berdasarkan pada penelitian ini bahwa Sukuk tidak bisa dikategorikan sebagai utang piutang yang membawa kita pada bunga (riba) seperti obligasi yang selama ini dikenal dalam keuangan konvensional. Beberapa prinsip pokok dalam transaksi ini antara lain berupa penekanan pada perjanjan yang adil, anjuran atas sistem bagi hasil atau profit sharing, serta larangan terhadap riba, gharar dan maysir. Hasil penelitian Rudi Bambang Trisilo (2014) Penerapan Akad Pada Obligasi Syariah Dan Sukuk Negara (Surat Berharga Syariah Negara / SBSN) dengan hasil penelitian adanya underlying asset mempunyai fungsi terhadap kegiatan pertukaran riil yang menjadi dasar pencetakan SBSN, dan menjadi sebagian aspek pembeda diantara pencetakan surat utang dengan sukuk ${ }^{8}$. Penelitian oleh Melati Anjaswati (2016) yang berjudul tinjauan fiqih terhadap pelaksanaan sukuk negara ijarah sale and lease back di pasar modal syariah Indonesia, dengan hasil penerapan akad Sales and Lease Back sudah sesaui dengan akad ijarah (sewa) pada aturan Syariah Islam dalam rukun dan syarat yang berlaku, rukun dan syarat itu di antaranya: $A l$ muta'aqidain (dua pihak yang berakad). Imbalan/sewa/nominal, Manfaat serta Shighot, Ijab dan Qabul' .

Secara umum, hal yang membedakan antara penelitian terdahulu dengan penelitian yang akan penyusun laksanakan yaitu pada tujuan dan sasaran penelitian. Pada penelitian ini penyusun meneliti tentang akad ijarah - asset to be leased tetapi masih mempunyai kolerasi dengan ijarah - lease and back, serta penerapan bank dalam penggunaan akad tersebut, sehingga dapat menjawab beberapa rumusan masalah yang tersusun pada pembahasan sebelumnya.

Merujuk pada keputusan Ketua Badan Pengawas Pasar Modal dan Lembaga Keuangan (Bapepam - LK) Nomor KEP-181/BL/2009, Sukuk diartikan sebagai efek syariah berupa sertifikat atau bukti kepemilikan yang bernilai sama dan mewakili bagian penyertaan yang tidak terpisahkan atau tidak terbagi atas : (1) kepemilikan asset berwujud tertentu, (2) nilai manfaat dan jasa atas asset proyek tertentu atau aktivitas investasi tertentu, atau (3) kepemilikan atas asset proyek tertentu atau aktivitas investasi tertentu ${ }^{10}$.

Secara bahasa Arab penyebutan ijarah (sewa) adalah pengambilan atau pemanfaatan terhadap benda. Semua ulama bersepakat hukum menyewakan barang diperbolehkan,

\footnotetext{
${ }^{6}$ Faizul Rahman, Ardi Paminto, and Maryam Nadir, "Pengaruh Harga Sukuk Negara Ritel Seri SR-005, Tingkat Inflasi Dan BI RATE Terhadap Tingkat Permintaan Sukuk Negara Ritel Seri SR-005," Jurnal Manajemen 8, no. 1 (2016): 19-29.

${ }^{7}$ SH Intisar, Pelaksanaan Akad Ijarah Asset to Be Leased Surat Berharga Syariah Negara Ritel (Seri SR008), 2017.

${ }^{8}$ Rudi Bambang Trisilo, "Penerapan Akad Pada Obligasi Syariah Dan Sukuk Negara (Surat Berharga Syariah Negara / SBSN)," Ekonomi dan Hukum Islam 4, no. 1 (2014): 18-38.

${ }^{9}$ Melati Anjaswati et al., "Jurnal Fiqih Transaksi Keuangan Kontemporer” 1, no. 1 (2016): 1-29.

${ }^{10}$ Fatwa DSN-MUI, Nomor: 76/DSN-MUI/VI/2010 Tentang Ijarah-Asset To Be Leased (Jakarta, 2010).
} 
kemudian akadnya diikrarkan oleh kedua pihak. Kalau akad sudah dianggap sah secara syariat maka dari kedua belah pihak tidak boleh ada yang membatalkan akad tersebut, walaupun adanya suatu uzur yang dalami, terkecuali kalau ada sesuatu yang memang harus membatalkan akad. Kegiatan ijarah (sewa) didasarkan atas adanya beralihnya manfaat atas barang (hak guna), akan tetapi bukan beralih secara hak milik (kepemilikan). Jadi secara pokok ijarah tidak jauh beda dengan pokok dari jual beli, hanya saja yang membedakan terletak di objek transaksinya ${ }^{11}$.

Definisi dasar daripada ijarah (sewa) adalah sebagai hak untuk bisa mengambil manfaaat atas barang atau jasa tertentu setelah mencapai kesepakatan pembayaran. Dasar lain mengacu pada Fatwa Dewan Syariah Nasional (DSN) No.9/DSNMUI/IV/2000 tentang Pembiayaan Ijarah (sewa), ijarah adalah kontrak (akad) memindahkan kemanfaatan atas barang atau jasa dengan kurung waktu yang disepakati setelah melalui harga sewa, tanpa memindahkan hak kepemilikan atas barang tersebut ${ }^{12}$.

Beberapa dasar dari Al Qur'an maupun Hadits yang menjelaskan hukum dari pada diperbolehkannya menjalankan praktik ijarah (sewa) seperti pada QS. Al Qashash: 26

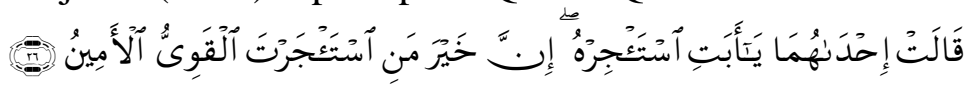

Salah seorang dari kedua wanita itu berkata: "Ya bapakku ambillah ia sebagai orang yang bekerja (pada kita), karena Sesungguhnya orang yang paling baik yang kamu ambil untuk bekerja (pada kita) ialah orang yang kuat lagi dapat dipercaya". ${ }^{13}$

QS. Al Zukhruf: 32

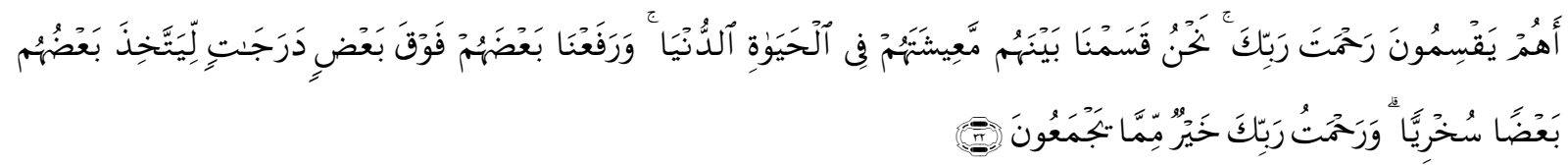

Apakah mereka yang membagi-bagi rahmat Tuhanmu? Kami telah menentukan antara mereka penghidupan mereka dalam kehidupan dunia, dan Kami telah meninggikan sebahagian mereka atas sebagian yang lain beberapa derajat, agar sebagian mereka dapat mempergunakan sebagian yang lain. dan rahmat Tuhanmu lebih baik dari apa yang mereka kumpulkan. $^{14}$

QS.At Thalaq: 6

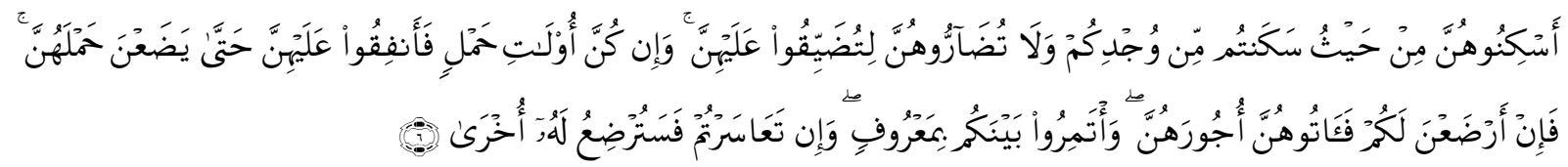

Tempatkanlah mereka (para isteri) di mana kamu bertempat tinggal menurut kemampuanmu dan janganlah kamu menyusahkan mereka untuk menyempitkan (hati) mereka. dan jika mereka (isteri-isteri yang sudah ditalaq) itu sedang hamil, Maka berikanlah kepada mereka nafkahnya hingga mereka bersalin, kemudian jika mereka menyusukan (anak-anak)mu untukmu Maka berikanlah kepada mereka upahnya, dan musyawarahkanlah di antara kamu (segala sesuatu) dengan baik; dan jika kamu menemui kesulitan Maka perempuan lain boleh menyusukan (anak itu) untuknya. ${ }^{15}$

Berdasarkan penjelasan fatwa AAOIFI yang pernah dikeluarkan memberikan perincian dari sudut pandang obyek akad, ada berbagai macam jenis akad yang bisa diterapkan. yaitu

\footnotetext{
${ }^{11}$ Hendi Suhendi, Fiqh Muamalah (Jakarta: Raja Grafindo Persada, 2011).

12 Dewan Syariah Nasional Majelis Ulama Indonesia (DSN-MUI), "Fatwa DSN Tentang Pembiayaan Ijarah," Himpunan Fatwa DSN MUI (2000): 4.

${ }^{13}$ Departemen Agama R. I., Al-Qur'an Dan Terjemahnya (Bandung: J-Art, 2005). H. 156

${ }^{14}$ Departemen Agama R. I., Al-Qur'an Dan Terjemahnya. H. 273

${ }^{15}$ Ibid. h. 139
} 
antara lain : Ijarah, Murabahah Salam ,Istishna', Musyarakah, Mudharabah, Wakalah, Muzara'ah, Musaqah ${ }^{16}$.

Sukuk ijarah merupakan sukuk yang dalam hal fleksibilitasnya mempunyai tingkat yang cukup tinggi. Proses pengambilan manfaat oleh penyewa dalam sewa ijarah tidak sama sekali berkaitan dengan pembayaran dari sewa iarah itu sendiri. Maksud sewa ijarah mempunyai tingkat fleksibilitas ini adalah pihak dari penerbit dan para investor dapat menyesuaikan tujuan yang berbeda dengan mengubah bentuk-bentuk yang berbeda dari tingkat kontrak dan sukuk. ${ }^{17}$

Tujuan dari penelitian ini pertama Untuk mengetahui pengimplementasian sukuk ritel menggunakan akad ijarah - asset to be leased. Kedua untuk mengetahui apa saja kendala yang dialami oleh pihak bank dalam mengimplementasikan produk sukuk ritel.

\section{B. Metode Penelitian}

Penulisan artikel ini bersifat deskriptif dan menerapkan content analiysis. Berbagai pertimbangan kenapa penulis menerapkan metode tersebut karena dalam karya ini penulis berupaya membuat landasan teori sebagai dasar berfikir agar penulisan ini focus sesuai dengan kondisi kenyataan yang terjadi di lokasi dengan mempertimbangkan pada penelitianpenelitian terdahulu supaya dapat memberikan acuan dalam menentukan dasar awal melakukan penelitian dan sebagai bahan pertimbangan dari hasil penelitian. Oleh karena itu memaparkan hasil observasi pelaksanaan bahasan penelitian kemudian dijelaskan dalam bentuk narasi dan skema pelaksanaannya. Penilitian ini dilakukan di PT. Bank Syariah Mandiri cabang Jombang, tepatnya di Ruko Cempaka Mas Blok A8-9 Jl. Soekarnno Hatta No.1 Jombang.

Menurut Hamidi, penelitian kualitatif adalah penyajian data dalam bentuk uraian kalimat, paparan yang mendalam atau detail hasil wawanara dan observasi yang diperoleh dari responden. pandangan penelitian yang mengemukaan hal seperti ini biasa dibilang dengan sebutan pandangan perspektif deskriptif, yakni data yang ditampilkan dengan menguraikan secarfa deskriptif. Sedangkan penjabaran mengenai pendekatan dan perspektif penelitian ini berupa deskripsi, uraian detail, cerita rinci oleh para informan penelitian ${ }^{18}$.

Sedangkan pendapat dari Arikunto yang dinamakan dengan penelitian deskriptif adalah penelitian dengan bertujuan untuk menghimpun segala informasi tentang kondisi yang ada, yakni kondisi menuntut seadanya pada saat penelitian dilangsungkan. Adanya penelitian deskriptif ini bertujuan untuk membuat uraian secara detail, gambaran yang disajikan dengan sistematis, data yang paling terbaru, dan sesuai dengan kondisi fakta yang ada, sifat serta keterkaitan fenomena yang ada. ${ }^{19}$.

\section{Hasil dan Pembahasan \\ Implementasi Akad Ijarah - Asset To Be Leased}

Bank di Indoensia yang bergerak pada kegiatan perbankan Syariah dengan menjadi agen Penjual di Pasar Perdana dikuasai Bank Syariah Mandiri, dimana dia menawarkan produk Surat Berharga Syariah Negara (SBSN) yang dikenal dengan sukuk negara ritel. Sukuk

16 AAOIFI, Statement on the Purpose and Calculation of the Capital Adequacy, Manama, Bahrain: Accounting and Auditing Organization for Islamic Utions, 2003.

${ }^{17}$ muhammad Ardi, "Pengaruh Sukuk terhadap Pertumbuhan Ekonomi Indonesia," Iqtishaduna 9, no. 1 (2018): 1-16.

${ }^{18}$ Hamidi, Penelitian Kualitatif Pendekatan Praktis Penulisan Proposal Dan Laporan Penelitian (Malang: UMM Press, 2010): 58.

${ }^{19}$ Suharsimi Arikunto, Prosedur Penelitian Suatu Pendekatan Praktek (Jakarta: Rineka Cipta, 2006): 150. 
menurut AAOIFI 2003 No.17 merupakan sertifikat yang menempatkan kegunaan hak milik dengan nilai sama sebagai shares and right dalam asset tetap (tangible assets), manfaat (usufructs), dan pengkhidmatan (service) atau suatu kewajaran dari proyek atau investasi tertentu. Banyak yang mempersamakan antara sukuk dengan surat obligasi (bond) dan bahkan produk-produk pasar modal konvensional lainnya, walaupun produknya agak berbeda dengan sifatnya.

Bank Syariah mandiri berkembang sebagai bank yang berhasil kolaborasi antara prinsip dari usaha dengan memadukan nilai-nilai keagamaan yang mendasri dalam operasional kegiatanya. Keserasisan keduanya inilah yang sangat berpengaruh terhadap BSM dengan menjadi keunggulan dalam berkiprah sebagai perbankan Syariah. Selain itu juga BSM tampil Bersama dalam menuju pembangunan perekonomian Indonesia menjadi lebih baik.

Penerapan akad Ijarah - Asset To Be Leased yang diterapkan Bank Syariah Mandiri untuk sukuk ritel dengan menggunakan akad Ijarah - Asset To Be Leased yakni akad persewaan antara emiten (pemerintah) dengan para investor (nasabah) dengan syarat bahwa Underlying Assets digunakan sebagai agunan (jaminan) tidak boleh dijadikan barang untuk jual beli oleh investor, dan kalo sudah melewati waktu jatuh tempo harus dijual kembali.

Sebenarnya dalam hal ini bisa dilihat bahwa akad yang digunakan merupakan kombinasi dari dua akad, yakni akad sewa (ijarah) dan jual beli (al-bay'). Dalam hubungannya dengan akad jual beli (al-bay') disebut jual beli bersyarat (Bay' Wafa') artinya adalah investor berhak untuk memanfaatkan barang itu, akan tetapi hanya kepada emitren barang tersebut bisa dijual tidak bisa dijual kepada orang lain, dan emiten juga berkewajiban untuk membayar kembali lunas harga jual semula kepada investor, dan kewajiban investor untuk menjualnya kembali kepada emiten pada masa sudah jatuh tempo. Hal ini juga diterapkan oleh BSM dalam mengimplementasikan akad Ijarah - Asset To Be Leased terhadap transaksi sukuk ritel yang dijalankannya.

Pemerintah menetapkan Bank Syariah Mandiri sebagai Agen Penjual Sukuk Negara Ritel. Bank Syariah Mandiri menawarkan bermacam-macam produk Sukuk Negara Ritel seperti pada berikut :

Tabel 1. Produk Sukuk Negara Ritel

\begin{tabular}{|c|c|}
\hline Sukuk Negara Ritel Seri SR-011 & SBSN tanpa warkat (scriptless) \\
\hline Akad & Ijarah-Asset To Be Leased \\
\hline Underlying Asset & $\begin{array}{l}\quad \text { Proyek dalam APBN tahun } 2019 \\
\quad \text { Barang Milik Negara (BMN) berupa } \\
\text { tanah dan/atau bangunan } \\
\text { Menteri Keuangan menetapkan rincian Proyek } \\
\text { dan BMN yang akan digunakan sebagai Aset } \\
\text { SBSN dalam rangka penerbitan Sukuk Negara } \\
\text { Ritel seri SR-011 }\end{array}$ \\
\hline Issuer & Perusahaaan Penerbit SBSN Indonesia \\
\hline Investor & $\begin{array}{l}\text { Individu Warga Negara Indonesia (WNI) yang } \\
\text { telah memiliki rekening di Mandiri Syariah }\end{array}$ \\
\hline Nilai Nominal Per Unit & Rp1 juta \\
\hline $\begin{array}{l}\text { Nilai Nominal Pemesanan } \\
\text { pembelian }\end{array}$ & $\begin{array}{l}\text { Rp1 juta (1 unit) dan kelipatan Rp1 juta serta } \\
\text { batas maksimum sebesar Rp3 miliar }\end{array}$ \\
\hline Tenor & 3 tahun \\
\hline Tradability & $\begin{array}{l}\text { Tradable, dengan holding period selama } 2 \text { (dua) } \\
\text { periode kupon terhitung mulai tanggal } 28 \text { Maret } \\
2019 \text { sampai dengan } 10 \text { Juni } 2019\end{array}$ \\
\hline Kupon & $\begin{array}{l}\text { • } \mathbf{8 , 0 5} \% \text { p.a. } \\
\text { Pembayaran kupon dilakukan secara periodik } \\
\text { setiap bulan pada tanggal } 10 \text { (sepuluh). Apabila } \\
\text { tanggal } 10 \text { (sepuluh) jatuh pada hari libur maka } \\
\text { akan dibayarkan pada hari kerja berikutnya. }\end{array}$ \\
\hline Masa Penawaran & $\begin{array}{l}\text { Mandiri Syariah hanya melayani pemesanan } \\
\text { pembelian dari tanggal } 1 \text { Maret s.d. } 19 \text { Maret } \\
2019 \text {, mulai jam 08.00 WIB s.d. } 13.00 \text { WIB. } \\
\text { Khusus tanggal } 19 \text { Maret 2019, Mandiri } \\
\text { Syariah melayani mulai jam 08.00 WIB s.d. } \\
\text { 11.00 WIB }\end{array}$ \\
\hline Tanggal Penerbitan & 28 Maret 2019 \\
\hline Tanggal Jatuh Tempo & 10 Maret 2022 \\
\hline
\end{tabular}




\begin{tabular}{|c|c|}
\hline Tanggal Penjatahan & 26 Maret 2019 \\
\hline Tanggal Setelmen & 28 Maret 2019 \\
\hline Tanggal Pencatatan di Bursa & 29 Maret 2019 \\
\hline Nominal Pelunasan & At par $(100 \%)$, bullet payment \\
\hline Agen Pembayar & Bank Indonesia \\
\hline Subregistry| & $\begin{array}{l}\text { Kustodian Sentral Efek Indonesia (KSEI) melalui } \\
\text { Partisipan/Nasabah Subregistry: Kustodian } \\
\text { Bank Bukopin }\end{array}$ \\
\hline \multicolumn{2}{|l|}{ Pasar Perdana: } \\
\hline Biaya & $\begin{array}{l}\text { 1. Biaya Materai untuk Pernyataan dan } \\
\text { Kuasa dan Pembukaan Rekening Surat } \\
\text { Berharga di Kustodian Bank Bukopin } \\
\text { 2. Biaya penyimpanan Efek di Kustodian } \\
\text { Bank Bukopin sebesar 0.025\% p.a } \\
\text { minimum Rp5.000/bulan ditambah } \\
\text { Pajak Pertambahan Nilai (PPN). Biaya } \\
\text { penyimpanan Efek dibayarkan setiap } \\
\text { bulan dengan pemotongan secara } \\
\text { langsung dari Imbalan/Kupon SR- } \\
\text { 011 yang diterima nasabah. } \\
\text { Biaya Dana Perlindungan Pemodal yang } \\
\text { dibayarkan hanya } 1 \text { (satu) kali dalam } \\
\text { setahun dengan masa perlindungan } 1 \text { (satu) } \\
\text { tahun. Biaya Dana Perlindungan Pemodal } \\
\text { dikenakan sebesar perkalian Faktor Resiko } \\
\text { dengan 0,001\% dari rata-rata bulanan total SR- } \\
\text { 011 nasabah pada tahun sebelumnya. Biaya } \\
\text { Dana Perlindungan Pemodal dibayarkan oleh } \\
\text { nasabah dengan memotong penerimaan } \\
\text { kupon SR-011 pada bulan Februari setiap } \\
\text { tahunnya sampai dengan jatuh tempo. }\end{array}$ \\
\hline Pajak & Pajak Kupon sebesar 15\% (PPh Final) \\
\hline
\end{tabular}

Pasar Sekunder

\begin{tabular}{|c|c|}
\hline 1. Nasabah Beli & \\
\hline Biaya & $\begin{array}{l}\text { 1. Biaya Transaksi Rp } 25.000 \text { per transaksi. } \\
\text { 2. Bea Meterai untuk Surat Pernyataan dan } \\
\text { Kuasa Pembukaan Rekening Efek di Bank } \\
\text { Kustodian. }\end{array}$ \\
\hline
\end{tabular}

Biaya Kupon Berjalan (accrued return).

\begin{tabular}{|c|c|}
\hline Pajak & - \\
\hline 2. Nasabah Jual & \\
\hline Biaya & $\begin{array}{l}\text { 1. Biaya Transaksi Rp } 25.000 \text { per transaksi. } \\
\text { Apabila nasabah ingin memindahkan } \\
\text { dananya ke Rekening Efek pada Bank } \\
\text { Kustodian dan/atau Sekuritas lain di luar } \\
\text { Kustodian Bank Bukopin (against }\end{array}$ \\
\hline
\end{tabular}

\begin{tabular}{|c|c|}
\hline & $\begin{array}{l}\text { payment) maka dikenakan tambahan } \\
\text { biaya Rp25.000,- per transaksi. } \\
\text { Biaya penyimpanan Efek di Kustodian Bank } \\
\text { Bukopin sebesar } 0.025 \% \text { p.a minimum Rp5.000 } \\
\text { ditambah Pajak Pertambahan Nilai (PPN), } \\
\text { apabila nasabah menjual keseluruhan SR-011. }\end{array}$ \\
\hline Pajak & $\begin{array}{l}\text { 1. 1. Apabila dijual pada harga premium, } \\
\text { maka dikenakan pajak capital gain dan } \\
\text { kupon berjalan (accrued return) masing- } \\
\text { masing sebesar } 15 \% \text { (PPh Non Final). } \\
\text { 2. Apabila dijual pada harga par, maka } \\
\text { dikenakan pajak kupon berjalan (accrued } \\
\text { return) sebesar } 15 \% \text { (PPh Non Final). } \\
\text { 3. Apabila dijual pada harga discount, maka } \\
\text { dikenakan pajak atas selisih antara } \\
\text { kupon berjalan (accrued return) dan total } \\
\text { capital loss sebesar } 15 \% \text { (PPh Non } \\
\text { Final). } \\
\text { Pajak tersebut diperhitungkan pada SPT } \\
\text { Tahunan. }\end{array}$ \\
\hline
\end{tabular}

Sumber: BSM Cabang Jombang

Jurnal Baabu Al-ilmi Volume 5 No. 2 Oktober Tahun 2020 | 196 
Setelah penenjukkan BSM sebagai agen penjualan sukuk dikalangan investor, BSM memualai melakukan mekanisme dalam bertransaksi sukuk, sebagaimana tahapan berikut yang didapat dari BSM Cabang Jombang:

1) Nasabah Mengisi Form Aplikasi Pemesanan Sukuk Negara Ritel

2) Memeriksa Kelengkapan data Formulir nasabah

3) Melakukan Pembayaran ke Teller (setor dana ke rekening nasabah).

4) Memblokir dana nasabah sebesar nilai pembelian SR-011 di-iBSM dan memastikan rekening nasabah tidak dapat digunakan untuk fasilitas autodebet, autopayment maupun autosave.

5) Input data nasabah pada $A S / 400$ dan lakukan approval input oleh OM.

6) Mengirim secara harian ke OPD-KP (jika ada transaksi pemesanan) berupa 2 bundel dokumen untuk setiap nasabah.

Setelah nasabah selesai dalam pembukaan rekening dalam pemesanan sukuk negara, selanjutnya pihak BSM melanjutkan pemesanan tersebut dalam pelimpahan dana dengan Langkah;

1) Kantor pusat akan melakukan pembukaan blokir dana nasabah dan langsung masuk ke Rekening Perantara Pembelian Sukuk Ritel Cabang (IDR145020015XXXX).

2) Cabang melakukan rekonsialisi dana pada Rekening Perantara Pembelian Sukuk tersebut dengan data penjatahan di Modul Sukuk AS400.

3) Jika sudah benar, Cabang mengirimkan dana secara bulk ke Rekening Perantara Pembelian Sukuk Ritel KP (IDR1450200150001)

Proses setelah pelimpahan dana ke perantara selesai, kantor cabang menyampaikan bukti dalam pembelian sukuk kepada nasabah.

1) Mengirim Konfirmasi Pembelian Sukuk Negara Ritel Nasabah.

2) Menerima Konfirmasi Sukuk Negara Ritel untuk diserahkan ke CS.

3) Copy Konfirmasi Pembelian Sukuk Negara Ritel dan berikan ke nasabah. Pembelian min. Rp100 juta dikirim langsung ke nasabah. Pembelian di bawah Rp100 juta, nasabah mengambil ke Cabang BSM.

4) Menandatangani Buku admistrasi serah terima Konfirmasi Pembelian Sukuk Negara Ritel Nasabah.

Mengenai imbalan pembelian sukuk, tahapan sebagai berikut;

1) Setiap bulan Kantor Pusat menerima data imbalan/kupon dari Bank dan memeriksa kebenaran isi data lampiran pembayaran kupon terhadap Data Investor di AS/400.

2) Melakukan posting ke rekening-rekening investor untuk pembayaran kupon dengan menggunakan sistem transfer one to many.

3) Nasabah menerima dana kupon pada rekening pembayaran kupon nasabah.

Setelah semua tahapan selesai dilakukan, tinggal bagaimana kalau terjadi pembayaran pokok pada saat jatuh tempo;

1) Kantor Pusat menerima data pembayaran nominal (pokok) dari Bank Kustodi dan memeriksa kebenaran isi data lampiran pembayaran terhadap Data Investor di Modul Sukuk.

2) Melakukan posting ke rekening-rekening investor untuk pembayaran nominal pokok dengan menggunakan sistem transfer one to many.

3) Nasabah menerima dana pokok Sukuk Negara Ritel pada rekening pembayaran kupon/pokok Sukuk Negara Ritel nasabah. 
Dalam transaksi Sukuk Ritel tidak hanya menggunakan akad ijarah saja, terdapat akad kafalah dan wakalah. akad kafalah dikeluarkan pada saat pengeluaran surat emisi digunakan jaminan terhadap unit sukuk yang dikeluarkan. Sedangkan Akad wakalah dimasksudkan pada saat pengeluaran sukuk sebagai wakil dari proses penyewaan sukuk kepada penjamin emisi.

Hal yang tidak kalah penting dalam transaksi sukuk ritel adalah adanya Underlying Asset (aset penjamin) mengapa demikian, karena yang membuat beda antara sukuk dengan obligasi konvensional. Pada obligasi konvensional, obligasi digunakan untuk instrumen hutang piutang dengan hasil yang samar-samar menyerupai riba (bunga) dimana Syariah islam tidak memperbolehkan praktik seperti itu. Lain halnya dengan obligasi, sukuk bukan efek berdasar hutang tetapi berdasar pada keikutsertaan kepemilikan sementara. Kegiatan yang terjalin antara investor dengan Lembaga yang mengeluarkan sukuk bukan beasas pada pinjam meminjam tetapi investor mengikutkan modalnya terhadap kepemilikan asset yang dibiaayai oleh sukuk sebgai wakil aset yang wujud dan jelas salam kegiatan ekonomi dan jasa. Sukuk memakai kontrak (akad) ijarah (sewa) yakni pemindahan kembali kepemilikan atas manfaat aset tersebut kepada pemilik aset tetap dikuasai berdasarkan purchase and sale undertaking agreement (janji untuk membeli) ${ }^{20}$.

Adapun beberapa kendala yang dihadapi dalam pelaksanaan produk investasi jasa sukuk ritel:

a. Masih minimnya pengetahuan masyarakat mengenai apa itu sukuk.

Sukuk merupakan hal yang masih terdengar asing dalam kalangan masyarakat sekitar bank, sehingga untuk bisa mendapat kepercayaan nasabah baru untuk berinvestasi di bidang ini, bank cukup mengalami kesulitan. Permasalahn ini dapat diatasi dengan pendekatan yang lebih intensif kepada nasabah, hal yang dilakukan oleh BSM adalah dengan menerapkan Sales KIT yakni promosi lisan yang dilakukan oleh customer service di sela akhir pelayanan terhadap nasabah.

b. Kelengkapan Data Administrasi

Kelengkapan data administrasi yang merupakan syarat-syarat dalam pengajuan proses sukuk ritel masih minim, masyarakat yang awalnya memang belum banyak paham dan ingin menjadi nasabah sukuk terkadang tidak mau banyak direpotkan dengan segala macam persyaratan-persyaratan yang diajukan bank. Permasalahan ini dapat diatasi dengan memberikan pengertian yang baik kepada nasabah, bahwa persyaratanpersyaratan yang dicantumkan akan berkaitan dengan keabsahan serta kelegalan transaksi sukuk ritel.

c. Tenggang waktu yang terbatas.

Tenggang waktu pendaftaran calon nasabah sukuk ritel adalah satu bulan. Dan waktu yang biasa diberikan adalah satu bulan. Dengan tenggang waktu yang terbatas untuk menarik nasabah pemerintah diharapkan melakukan promosi yang lebih intensif melalui iklan, brosur, iternet, dan juga kerjasama antara kantor cabang, maupun kantor cabang pembantu yang lain.

\section{Simpulan}

Berdasarkan hasil penelitian yang telah dideskripsikan, dapat ditarik kesimpulan bahwa implementasi akad Ijarah - Asset To Be Leased Pada transaksi sukuk ritel juga terdapat akad jual beli (al-bay') atas underlying asset, serta penggunaan akad kafalah

${ }^{20}$ Khusna Khanifa Nurma, Tinjauan Hukum Islam Terhadap Transaksi Jual Beli Sukuk Ritel Menggunakan Sistem Akad Ijarah Serta Relevansinya Dengan Perlindungan Investor (Semarang, 2012). 
dikeluarkan pada saat pengeluaran surat emisi digunakan jaminan terhadap unit sukuk yang dikeluarkan. Sedangkan Akad wakalah dimasksudkan pada saat pengeluaran sukuk sebagai wakil dari proses penyewaan sukuk kepada penjamin emisi.

Kendala-kendala yang dihadapi implementasi sukuk ritel yakni , a). Masyarakat sekitar bank yang masih banyak belum mengetahui tentang apa itu sukuk ritel, b). Kurangnya kesadaran nasabah akan kelengkapan data administrasi sukuk ritel, c). Serta, batas tenggang waktu sukuk ritel. Akan tetapi selama ditangani dengan baik tidak akan menghambat perluasan dan peningkatan transaksi sukuk ritel. Hal ini juga tidak lepas dari usaha SDI secara maksimal.

\section{Daftar Pustaka}

AAOIFI. Statement on the Purpose and Calculation of the Capital Adequacy, Manama, Bahrain: Accounting and Auditing Organization for Islamic Utions, 2003.

Anjaswati, Melati, Tuti Suryani, Program Studi, Perbankan Syariah, Ijarah Sale, and Lease Back. "Jurnal Fiqih Transaksi Keuangan Kontemporer" 1, no. 1 (2016): 1-29.

Ardi, Muhammad. "Pengaruh Sukuk terhadap Pertumbuhan Ekonomi Indonesia." Iqtishaduna 9, no. 1 (2018): 1-16.

Arikunto, Suharsimi. Prosedur Penelitian Suatu Pendekatan Praktek. Jakarta: Rineka Cipta, 2006.

Departemen Agama R. I. Al-Qur'an dan Terjemahnya. Bandung: J-Art, 2005.

Dewan Syariah Nasional Majelis Ulama Indonesia (DSN-MUI). "Fatwa DSN Tentang Pembiayaan Ijarah." Himpunan Fatwa DSN MUI (2000): 4.

Faniyah, Iyah. Kepastian Hukum Sukuk Negara Sebagai Instrumen Investasi Di Indonesia. Edited by Laurensius Arliman Simbolon. Pertama. Sleman: Deepublish, 2018.

Fatwa DSN-MUI. Nomor: 76/DSN-MUI/VI/2010 Tentang Ijarah - Asset To Be Leased. Jakarta, 2010.

Hamidi. Penelitian Kualitatif Pendekatan Praktis Penulisan Proposal Dan Laporan Penelitian. Malang: UMM Press, 2010.

Hasibuan, Malayu S.P. Dasar-Dasar Perbankan. Jakarta: Bumi Aksara, 2009.

Intisar, SH. Pelaksanaan Akad Ijarah Asset to Be Leased Surat Berharga Syariah Negara Ritel (Seri SR-008), 2017.

Jurnal, Al-Tijary, Ekonomi Dan, Bisnis Islam, Angrum Pratiwi, Fakultas Ekonomi, Dan Bisnis, Islam Samarinda, Dedy Mainata, Rizky Suci, and Ramadayanti Fakultas Ekonomi. "Peran Sukuk Negara Dalam Pembiayaan Infrastruktur." core.ac.uk 2, no. 2 (2017): 155-176.

Madiri Syariah. "Sukuk Negara Retail."

Nurma, Khusna Khanifa. Tinjauan Hukum Islam Terhadap Transaksi Jual Beli Sukuk Ritel Menggunakan Sistem Akad Ijarah Serta Relevansinya Dengan Perlindungan Investor. Semarang, 2012.

Rahman, Faizul, Ardi Paminto, and Maryam Nadir. "Pengaruh Harga Sukuk Negara Ritel Seri SR-005, Tingkat Inflasi Dan BI RATE Terhadap Tingkat Permintaan Sukuk Negara Ritel Seri SR-005.” Jurnal Manajemen 8, no. 1 (2016): 19-29.

RI, Departemen Agama. Al-Quran Dan Terjemahnya. Jakarta: Gema Insani press, 2003.

Soemitra, Andri. Bank \& Lembaga Keuangan Syariah. Jakarta: Prenada Media, 2017. 
Suhendi, Hendi. Fiqh Muamalah. Jakarta: Raja Grafindo Persada, 2011.

Trisilo, Rudi Bambang. "Penerapan Akad Pada Obligasi Syariah dan Sukuk Negara (Surat Berharga Syariah Negara / SBSN).” Ekonomi dan Hukum Islam 4, no. 1 (2014): 1838. 